\title{
The Re-Recognition of the Relationship between Mathematical Knowledge and Ability Based on Key Competencies and Values
}

\author{
Jingxian Wu: School of Mathematical Sciences, University of Jinan, Jinan, Shandong 250022, P R China. \\ ¿Shurong Sun: School of Mathematical Sciences, University of Jinan, Jinan, Shandong 250022, P R China. \\ Zhenlai Han: School of Mathematical Sciences, University of Jinan, Jinan, Shandong 250022, P R China.
}

\begin{abstract}
In the current situation that ability is more and more valued, teaching process should take the key competencies of mathematics as the frame, realize the vividness, rigour and applicability of mathematics knowledge, identify these relationships that mathematical knowledge is the carrier of ability,mathematical ability is the sublimation of knowledge,mathematical knowledge and ability should be integrated as well as mathematical thought is the bridge of mathematical knowledge and ability so as to better cultivate key competencies of mathematics.
\end{abstract}

Key words: Mathematical knowledge, Mathematical ability, Key competencies of mathematics, Key competencies.

\section{Introduction}

ey competencies has been concerned since it was proposed, which has been discussed all the time, and sweep the country and abroad.The Latin word for "competencies" comes from virtus, which refers to moral excellence, which focuses on what people can do rather than what they know (Weinert, 2001).Key competencies is defined in China as "the necessary character and key ability for students to adapt to social development and lifelong development" (Ministry of Education, 2014)

. From "double-base(basic knowledge and skill)" to "three-dimensional goal(knowledge and skills,process and steps,emotional attitude and values)" to key competencies today, ability has become the top priority, while knowledge seems to be gradually abandoned.Facing the phenomenon that the role of knowledge is constantly weakened, we can't help asking: isn't knowledge part of competencies?Specific to key competencies of discipline, take mathematics as an example to discuss the status and significance of mathematical knowledge and correctly handle the relationship between learning mathematical knowledge and improving mathematical ability, so as to truly understand the core quality.

\section{Define the Characteristics of Mathematical Knowledge}

Mathematics comes from life and applies to life. To some extent, mathematical knowledge is an objective reflection of the world.Although mastering knowledge is not the ultimate purpose of cultivating students, all the goals should be based on mastering knowledge. The reason for the acquired difference between students is the varying level of ability on account of the totally different view of knowledge.Therefore, mathematical knowledge has a fundamental impact on people's mathematical learning, but also a fundamental influence. 


\subsection{Vividness of Mathematical Knowledge}

Mathematical knowledge is not made up of lots of Arabic numerals which are complicated and boring,but consist of many vivid symbols. Although the abstraction of mathematical knowledge is widely recognized, the author believes that it is the abstraction that makes mathematical knowledge vivid.It is necessary to comprehend mathematical concepts, symbols and geometric figures by the ways of mathematical thoughts such as combination of numbers and shapes, inductive reasoning and modeling, because they are too abstract.Such transformation is a process that reflects its vividness

For example, calculate the maximum value of this function:

$$
f(x)=\sqrt{x^{2}+16}-\sqrt{x^{2}-4 x+13},
$$

There are two square roots in this problem, and the highest degree of the algebraic expression within the two square roots is quadratic, so it's very difficult to solve this problem purely computationally.this problem will be a lot easier if combine these two algebraic expressions with points and lines and rewrite them.

The function can be written as:

$$
\begin{aligned}
f(x) & =\sqrt{x^{2}+16}-\sqrt{x^{2}-4 x+13} \\
& =\sqrt{(x-0)^{2}+(0-4)^{2}}-\sqrt{(x-2)^{2}+(0-3)^{2}}
\end{aligned}
$$

Take $^{A(0,4)}, B(2,3), P(x, 0), P$ is a moving point on the $x$-axis, At this time, the function $f(x)$ can be viewed as the maximum difference between PA and PB.

In the plane rectangular coordinate system, this function is graphically expressed as:

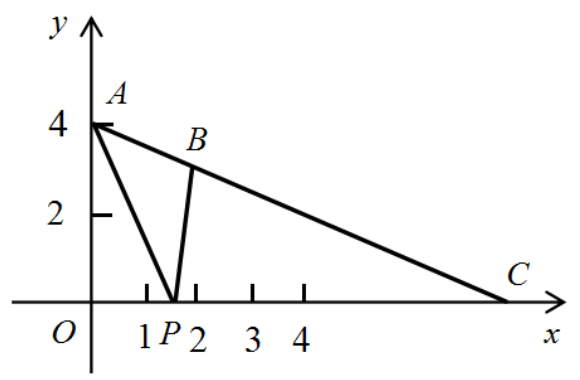

The points $P 、 A 、 B$ form $\triangle P A B$, the value of the function $f(x)$ is maximum of $|P A|-|P B|$

According to the triangle theorem that the difference between two sides is less than the third side, the Research in Social Sciences Vol. 1, No. 1, pp. 32-36

DOI: $10.53935 / 2641-5305 . v 1 i 1.5$ Corresponding Author: Shurong Sun Email: sshrong@163.com Funding: This study received no specific financial support.

Acknowledgment: This paper is the stage achievement of Jinan University Graduate Education Innovation Project "Research on Evaluation Criteria and System of Graduate Education Quality for Professional Degrees in Shandong Province under the Background of "Double-first-class"Construction" (No.JDYl601) "Double-first-class"Construction" (No. JDY1601) and "Research on Construction and Implementation of Quality Guarantee System for Graduate Education of Master of Education"
(No. JDY1707). (No. JDY1707).

Article History:
Received: 13 August 2018

Revised: 20 September 2018

Accepted: 25 October 2018

Published: 23 November 2018

() 2018 by the authors; licensee Academic Publishing Group

line of line segment $A B$ intersects the $x$-axis,

According to the Pythagorean theorem,the following conclusion can be reached:

$$
\begin{aligned}
f(x) & =|C A|-|C B|=|A B| \\
& =\sqrt{(4-3)^{2}+2^{2}} \\
& =\sqrt{5}
\end{aligned}
$$

This is a typical example which adapt the idea of combining numbers with shapes.In the process of teaching, students should be guided to construct the relationship between number and form.Knowledge has "appearance"through the combination of digital symbols and graphics, which is convenient for students to observe, imagine and evaluate. 


\subsection{Rigor of Mathematical Knowledge}

Mathematical rigor has two meanings: well-founded and accurate.This can be specific to two aspects : reasoning and calculation.Every step in the process of mathematical reasoning should be supported by corresponding axioms or theorems. The rigor of mathematical operations is easier to understand. Every mathematical problem may have multiple solutions, but there must be only one answer. Only when the reasoning process is watertight and the calculation is undoubtedly accurate can the final conclusion be reliable.

\subsection{Application of Mathematical Knowledge}

Charles Robert Darwin once said: "Mathematics is the foundation of all science."No other discipline or practice can exist independently separating oneself from mathematics. The computational and statistical methods learned in mathematics are indispensable in work and life.Some people think that many of the mathematical methods to solve problems are complex and esoteric and rarely used in reality.

Indeed,for those who do not engage in mathematical research in the future, there are not many opportunities to use the mathematical knowledge controlled in higher education, but the comprehensive and logical mathematical thinking in the learning process has an imperceptible impact on solving problems and benefits us for life.

\section{The Relation between Knowledge and Ability under the Framework of Mathematical Key Competencies \\ 3.1. Mathematical Knowledge Is the Carrier of Mathematical Ability}

"Key competencies system" is a new requirement for national talents in the knowledge era and a necessary character and key ability to cope with unpredictable situations in the new society.

Key competencies of mathematics has six basic elements: mathematical abstraction, intuitive imagination, logical reasoning, mathematical operation, data analysis and mathematical modeling. These abilities to be cultivated by mathematical key competencies are inseparable from the learning of mathematics knowledge. The accumulation of knowledge is directly related to the shaping of ability.If ability is a mountain, then knowledge is step to the top, is cornerstone to build the tall buildings of ability.

Of course, knowledge is also a double-edged sword.As an old saying goes : A coin has two sides. So does everything else.Not all mathematical knowledge can promote the improvement of mathematical ability.Taking key competencies as the framework, flexible knowledge integrated with mathematical thoughts will inevitably lead to the development of mathematical ability. On the contrary, spoon-feeding pedagogy will not only fail to meet the requirements of key competencies, but even lead to the degradation and disappearance of original ability.

\subsection{Mathematical Ability is the Sublimation of Mathematical Knowledge}

Cultivating ability is the purpose of absorbing knowledge, and improving ability is the result of applying knowledge. The most consistent point between key competencies and key competencies of mathematics is that people with corresponding abilities should be cultivated. However, the range of abilities required is different, and the content emphasized by mathematical core literacy is more local and specific.Both lead to the same destination, ability is the hard truth.Knowledge is to ability what theory is to practice, the objective of learning theory is to practice, and the process of practice also verifies the theory more profoundly.

For example, the mathematical knowledge of probability statistics has been continuously deepened from obligation education to higher education.

Solving one of the probability problems is actually the process of learning, for instance, when a coin falls on the ground, people who have learned about probability will immediately respond that the probability of heads or tails is one half, so you can say that you have the skill of probability statistics.

The process of knowledge sublimation mentioned above is very similar to mathematical modeling. Mathematical modeling, as the name implies, is to establish mathematical model, which is close to life."Compulsory education mathematics curriculum standard (2011 edition)" describes the significance of modeling: the establishment of model ideas is the basic way for students to experience and understand the connection between mathematics and the outside world (Compulsory Education Mathematics Curriculum Standard, 2011). Mathematical modeling mainly includes the following: identify the environmental issues of 
the topic to be addressed, Establish a mathematical connection between the problems and the individual's knowledge structure, simplify the problem and make appropriate assumptions, portrays the mathematical relationship of the problems by using mathematical tools, Through mathematical thoughts such as the combination of number and shape, reasoning and operation flexibly using knowledge to draw conclusions, and analyze its theoretical and practical significance.How to solve actual problems by mathematical methods, specifically, mathematical modeling, and next, analysis and calculation based on mathematical theories and method (Jiang et al., 2010).

For example, the annual interest rate of lump-sum deposit and withdrawal time deposit stipulated by agricultural bank of China in a certain period of last year is shown in the following table

\begin{tabular}{l|l|l|l|l}
\hline Deposit time & 1年 & 2年 & 3年 & 5年 \\
\hline $\begin{array}{l}\text { Annual interest } \\
\text { rate/\% }\end{array}$ & 2.25 & 2.43 & 2.70 & 2.88 \\
\hline
\end{tabular}

The interest that individual deposit obtains must pay tax $20 \%$ by law regulation, Mr. Smith deposits 10,000 yuan in the bank, maturity 3 years, after 3 years, what is the bank interest that Mr. Smith can obtain? How much is he dutiable? How much did he actually withdraw?

The sum of principal and interest after three years :

$10000 \times(100 \%+2.7 \%)^{3} \approx 10832$

Interest earned :

$10000 \times(100 \%+2.7 \%)^{3}-10000 \approx 832$

The tax payable :

$832 \times 20 \%=166.4$

Final amount :

$10832-166.4=10665.6$

Students with poor modeling ability will often use the method of $10000 \times 2.7 \% \times 3+10000$ to solve the problem when calculating the sum of principal and interest, which is to ignore the embodiment of the applicability of mathematical knowledge, and the mathematical ability of students will be divided into grades over time.

Mathematical modeling, as a new research method, is a process of sublimating knowledge and effectively cultivating mathematical ability, which can help students really transform knowledge in books into their own accomplishment.

Under the pressure of the difficulty of the topic and cooperation and competition, modeling will often stimulate the great potential that students themselves cannot expect. Students are usually limited to narrow perspectives within the framework of rules and regulations, so they will become broader in modeling and have a multi-faceted, multi-layered and multi-angle view of knowledge.

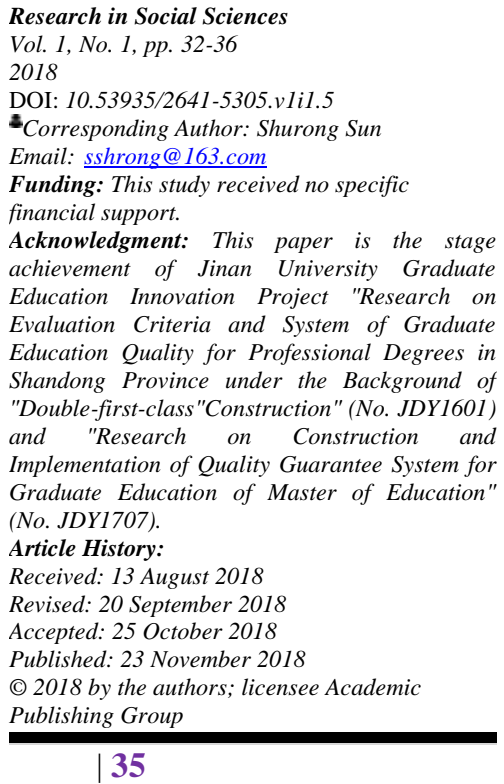

\subsection{Knowledge and Ability Should Be Regarded As One, and Mathematical Thought Is the Bridge between Them}

The mathematics knowledge and the student ability take the mathematics thought as the bridge, the three build a complete system.Mathematical thought endows knowledge with soul, just like a line connecting scattered knowledge, which helps students form a systematic knowledge framework and flexible learning methods, and effectively promotes the transformation of knowledge into ability.Knowledge and ability permeate each other in the process of mathematics learning, the two cannot exist independently. There is a relationship of dialectical unity between them.

The quality of mathematical knowledge is the quality of ability, the level of students' ability will also react on the further learning of knowledge.For example, it is the disconnection between theory and practice that renders students with high scores have low abilities, knowledge is separated from students' experiences. Their living experiences and ability are not enough to use knowledge, mathematical thought is not valued in the learning and application of knowledge. 


\section{Conclusion}

The key competencies has determined the new orientation of ability, which required teaching ideas and methods to make a corresponding transformation. The dialectical relationship between mathematical knowledge and ability has been explicit. How to realize the integration of knowledge and ability in mathematics classes and Cultivate the talents with key competencies of mathematics in the next step remain to be explored.

\section{References}

Weinert F E. (2001). Concept of competence: A conceptual clarification //Rychen,D S,Salganik L H. Defining and selecting key competencies. Seattle, WA: Hogrefe, Huber. pp: 45-65.

Ministry of Education, (2014). Opinions of ministry of education on comprehensively deepening curriculum reform and implementing the fundamental task of cultivating talents by virtue [no.4 of teaching foundation ii [2014]. Ministry of Education, 2014-04-08

Compulsory education mathematics curriculum standard (2011 edition). Ministry of education of the People's Republic of China. Beijing: Beijing Normal University Press, 2012.

QY. Jiang, JX. Xie, \& J. Ye, (2010). Mathematical model (Fourth Edition). Higher Education Press.

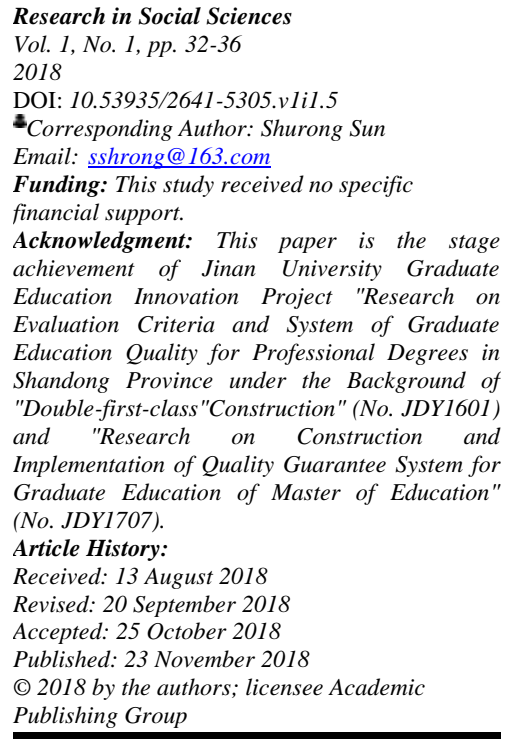

